Invited Paper

\title{
Listening, Care, and Collections as Data
}

\author{
Jacqueline Wernimont
}

\begin{abstract}
This paper takes the sonification (the translation into sound) of data from sterilization recommendations made under eugenic laws in the United States as a case study in navigating the terrain between a commitment to caring for and with impacted communities and the potential affordances and perils of using sensitive collections as data. The author discusses ways that feminist care ethics and collections as data research intersect in a digital humanities project.
\end{abstract}

Keywords: Collections as data, digital humanities, feminist care ethics, sonification, eugenics 


\section{INTRODUCTION}

In 1922 a middle-aged married man was sterilized in California after being diagnosed with "general paralysis." Otherwise known as paralytic dementia, his condition likely resulted from an untreated syphilis infection. As a man with a Spanish surname, he was $23 \%$ more likely to be sterilized by the state of California than his non-Latino counterparts. If he had been a woman, that risk would have been $59 \%$ more. ${ }^{1}$ I can tell you this story, and contextualize this individual's risk in relation to that of other psychiatric patients in California, because of a collaborative, multi-disciplinary effort to transform bureaucratic paperwork into data that can be analyzed and shared.

This man who was middle-aged in 1922 is statistically unlikely to still be alive, and state and federal privacy laws allow me to share his name and other information because more than 75 years have passed since the creation of the record suggesting his sterilization. ${ }^{2}$ I won't reproduce his file or add in more detail because I, and the research teams I work with, have made the decision to maintain patient privacy beyond the legal requirements. There are at least 17,361 other California sterilization survivors to whom we have made the same commitment and another 2,000+ whose information is still protected by privacy regulations. This essay takes the sonification (the translation of data into sound) of data from sterilization recommendations made under eugenic laws in the United States as a case study in navigating the terrain between a commitment to caring for and with impacted communities and the potential affordances and perils of using sensitive collections as data. It is about ways that feminist care ethics and collections as data research have intersected in this digital humanities project.

Throughout this piece, I will be talking about a prototype digital publication entitled Eugenic Rubicon: California's Sterilization Stories (Eugenic Rubicon hereafter), that was launched in 2017. ${ }^{3}$ Eugenic Rubicon draws from and complements the demographic and social science research on eugenic sterilization in California being carried out by the Sterilization and Social Justice Lab (SSJL) at the University of Michigan. Working with a unique collection-nearly 50,000 patient records from California from the period 1921 to 1953 -our project seeks to make this history visible and to make the

\footnotetext{
${ }^{1}$ Nicole L. Novak, Natalie Lira, Kate E. O’Connor, Siobán D. Harlow, Sharon L. R. Kardia, and Alexandra Minna Stern, "Disproportionate Sterilization of Latinos Under California's Eugenic Sterilization Program, 1920-1945," American Journal of Public Health 108, no. 5 (2018): 611-13, https://doi.org/10.2105/AJPH.2018.304369.

2 In personal correspondence with Alexandra Minna Stern as well as the State of California Archives, I learned that HIPAA regulations stipulate that we cannot reveal names, dates, and other identifying information from health care records, which includes both psychiatric and physical medicine. Additionally, we are governed by collections agreements with the State of California Archives, which now holds these records. For records less than 75 years old we are legally unable to tell individual stories of sterilization lest the individual be identified.

${ }^{3}$ As of October 2021, the first iteration of Eugenic Rubicon is available online as a prototype for our more recent work on a new site that is more national in scope. That project is ongoing as of this writing.
} 
dataset that we have developed accessible and interactive. These records were microfilmed by the California Department of State Hospitals in the 1970s and found in a closed facility by Alexandra Minna Stern, a co-PI on the Eugenic Rubicon project who has researched the history of eugenics in the United States. Stern's SSJL digitized these reels, which we use in compliance with state and university regulations to create a dataset that adheres to protocols around sensitive health data. These materials create opportunities as well as challenges for storytelling and humanizing stories of reproductive injustice. ${ }^{4}$ The materials also raise important questions about how we might balance a public right to know about practices within state-run facilities with the need to protect patients' rights to privacy regarding their own reproductive and mental health. ${ }^{5}$ In some cases, it seems as though the privacy guidelines protect the state more than they protect any individual patient or their communities. ${ }^{6}$ This essay takes up the possibility of using different modalities, sonification in particular, as a way of protecting privacy while also effectively sharing this history. In doing so, I connect this project to discussions of collections as data, ethics of care, and theories of archival care. I use these ideas to help assess the value and risks of engaging with this collection as data, specifically through sonification.

To better situate my own arguments and perspective, a few details: as mentioned above, Eugenic Rubicon is part of a larger, multigenerational project. I can only speak confidently about the part that I worked on directly. I am a neurotypical, white, cis-gender woman whose disabilities are not the sort typically targeted by eugenic sterilization. As such my interactions with this material are structured in and through multiple forms of privilege.

\section{ETHICS OF CARE AND FORMS OF LISTENING}

Within the Eugenic Rubicon collection are 19,995 sterilization recommendations and notes, which can help us to understand the scope, scale, and logic of 20th-century

\footnotetext{
${ }^{4}$ Alexandra Minna Stern, "Remembering Sara Rosas Garcia," Process: A Blog for American History, February 7, 2017, http://www.processhistory.org/sara-rosas-garcia/.

${ }^{5}$ Despite institutional and state concerns about privacy vis-a-vis these records, we have seen a remarkable lack of concern for them in their rediscovery and transmission. The California records were largely abandoned when Stern found the microfilm reels in the 2000s. They were lost again after she returned them to the state after having made authorized copies. The originals are lost as far as we know, and digital copies are now housed with the California State Archives.

${ }^{6}$ For more on this, including a discussion of lowa's perpetual privacy laws, which have become relevant as we've expanded this project, see: Susan C. Lawrence, Privacy and the Past: Research, Law, Archives, Ethics (New Jersey: Routledge, 2016); and Tonia Sutherland, "Remains," in Uncertain Archives: Critical Keywords for Big Data, ed. Nanna Bonde Thylstrup et al., (Cambridge: MIT, 2021), 433-42.
} 
eugenic sterilization. ${ }^{7}$ There are diagnoses, many of which read as spurious to a modern reader, and moments of insight into how consent was or was not secured for these operations. In the records we can see how 20th-century immigration fears, religious ideology, and pseudoscience played into large-scale sterilization efforts. We have evidence that individual people, like Sonoma State Hospital Superintendent Fred O. Butler, used their position of power to pursue sterilization for thousands of people deemed "mental defectives," including epileptics, women with what we now call postpartum depression, people "with a definite history of hereditary taint, and those who already had more children than they could properly care for." 8

As we have built the datasets and various tools for interfacing with them, we have invoked 'care' - care for the people who survived sterilization, care for impacted communities, even care for the records themselves - as one of our guiding principles. This has included the decision to not publish full versions of the records online, even when legally permissible. Digital materials circulate widely and are often re-rendered absent any careful contextualization that we might offer for them in our site. Such materials can be weaponized and used against communities to cause further harm. As scholars such as Susan Sontag, Sidonie Smith and Kay Schaffer, Saidiya Hartman, and Tonia Sutherland have repeatedly noted, even efforts to raise awareness through reproduction of the artifacts of violence can end up satisfying consumptive desires and "fantasies and voyeuristic pleasures," while simultaneously retraumatizing or perhaps newly traumatizing individuals, families, and communities. ${ }^{9}$ The Eugenic Rubicon project affirms the protection of individuals, families, and communities over the historical demands for knowledge.

At the same time, we recognize that "acts of listening and reading" to and about eugenic sterilizations may also serve to "seed new awareness, recognition, respect, and willingness to understand, acknowledge, and seek redress for rights violations." ${ }^{10} \mathrm{We}$ also care about the people who were so poorly cared for in the past. As Michelle Caswell and Marika Cifor argue, it is a powerful act to develop an "affective orientation to those about whom records are created;" we want to find ways to engender this kind of community care "about and for and with subjects" represented in these records. ${ }^{11}$

\footnotetext{
${ }^{7}$ Note that the numerical discrepancy between the 19,995 and the 17,361 mentioned in the opening is due to the additional 2,000+ records from after 1945. The Spanish surname dataset does not include post-1945 records.

${ }^{8}$ Fred O. Butler, "Report to Department of Institutions," (California State Printing Office, 1926).

${ }^{9}$ Kay Schaffer and Sidonie Smith, Human Rights and Narrated Lives: The Ethics of Recognition (New York: Palgrave Mcmillian, 2004), 26. See also: Susan Sontag's Regarding the Pain of Others, Saidiya Hartman's Scenes of Subjection: Terror, Slavery, and Self-Making in Nineteenth-Century America, and Tonia Sutherland's "'Making a Killing': On Race, Ritual, and (Re)Membering in Digital Culture," in Preservation, Digital Technology and Culture.

${ }^{10}$ Schaffer and Smith, Human Rights and Narrated Lives, 26

${ }^{11}$ Michelle Caswell and Marika Cifor, "From Human Rights to Feminist Ethics: Radical Empathy in the Archives," Archivaria 81 (Spring 2016): 23-43.
} 
Ethics of care is a philosophical and practical theory oriented against the ideal of the autonomous liberal individual and an ethics that derives from individual morality and interest. An ethics and praxis of care foregrounds context, interdependence, and listening. The early articulations of an ethics of care in the 1970s and 1980s by Carol Gilligan, Nel Noddings, Virginia Held, and others were largely rooted in white feminist interventions. However, insights about the centrality of context, interdependence, and listening to an ethics of care - and particularly the model of relationality that I find appealing in an ethic of care - are not unique to white feminist thought. If, as Joan Tronto writes, "care expresses relationships," then we can see the care ethics theorized in notions of relationality in Indigenous paradigms like those of Shawn Wilson, Mary Graham, or Elizabeth LaPensée. ${ }^{12}$

Consider also the models of "othermothering" and reciprocal relationality in the work of Black feminists like Barbara Smith and Patricia Hill Collins-or more recently that of Moya Bailey or Amarilys Estrella and Meryleen Mena. ${ }^{13}$ Additionally, work by postcolonial or decolonial scholars such as Daniela Agostino, Nalini Mooten, and Uma Narayan have drawn attention to the colonial and neocolonial structures of some care ethics, particularly those that depend on white, western, heteronormative notions of motherhood as a universal model of care, ignoring the commodification and appropriation of Black and brown women's care work both in the United States and globally. ${ }^{14}$ Mooten reminds us that, by contrast, a postcolonial ethics of care calls for each of us to be answerable in and for the specific encounters of our relationships; said another way, we must be answerable to the particular people with whom we engage rather than with caricatures or ideas about social categories. It also necessitates a recognition of the "irreducibility of perspectives," to ensure that value and connection

\footnotetext{
12 Joan Tronto, Caring Democracy: Markets, Equality and Justice (New York: NYU Press, 2013), p x.. See also: Shawn Wilson's Research Is Ceremony: Indigenous Research Methods, Mary Graham's "Aboriginal Notions of Relationality and Positionalism: A Reply to Weber" in Global Discourse, and Elizabeth LaPensée's "Relationality in Indigenous Food and Medicine Games" in Resilience: A Journal of Environmental Humanities.

${ }^{13}$ Barbara Smith, "Toward a Black Feminist Criticism," The Radical Teacher 7 (1978): 20-27; Patricia Hill Collins, Black Feminist Thought (New York: Routledge, 1990); Moya Bailey, "\#transform(Ing) DH Writing and Research: An Autoethnography of Digital Humanities and Feminist Ethics," Digital Humanities Quarterly 12, no. 4 (2015); Amarilys Estrella and Meryleen Mena, "Guest Post: Black Latinx Encuentros: Embodied Knowledge and Reciprocal Forms of Knowledge Sharing [Embodying Reciprocity Series]," Footnotes Blog, July 1, 2020, https://footnotesblog.com/2020/07/01/guest-post-black-latinx-encuentros-embodied-knowledge -and-reciprocal-forms-of-knowledge-sharing/

${ }^{14}$ Daniela Agostino, "Care," in Uncertain Archives: Critical Keywords for Big Data, ed. Nanna Bonde Thylstrup et al., (Cambridge: MIT, 2021); Nalini Mooten, "Toward a Postcolonial Ethics of Care," Dec. 18, 2016, https://ethicsofcare.org/wp-content/uploads/2016/12/Toward_a_Postcolonial_Ethics_of_Care.p df; Uma Narayan, "Colonialism and Its Others: Considerations On Rights and Care Discourses," Hypatia 10, no.2 (1995): 133-40.
} 
"is not fostered through a mirror projecting sameness onto the other." ${ }^{15}$ Care as the work of relationality is not assimilation and it cannot be essentialized. Agostinho reminds that consequently an ethics of care is not a panacea but is rather a method that we must employ ambivalently and always in relation if its potential for redress and dismantling is to be realized. ${ }^{16}$

As a multidisciplinary and intergenerational project, Eugenic Rubicon has entailed a great deal of listening. There are a number of ways in which this project has centered listening as a means of working toward mutual understanding, including: engaging with disability rights organizations, radical archivists, scholars, and community members who do related work; legal and congressional efforts to support reparations; and encounters with survivors and their families. These are efforts that we as a project team continue to make and to make better. We also introduce a different type of listening: listening to collections of official records through data sonification. Data sonification enables a listening toward (eschewing the more direct formulation 'listening to') eugenic histories as enacting an ethics of care. ${ }^{17}$ Our use of sound embodies a resistance to easy information gathering and to the kind of visual clarity sometimes imagined in data visualization and historical records. To listen toward, then, is to make formally and conceptually explicit the partial and heavily mediated access we have to historical actors and their experiences.

\section{WHY SONIFY?}

Feminist social movements and trauma-care paradigms both prominently feature the power of voice and storytelling, including the rights of survivors to tell their own stories on their own terms. ${ }^{18}$ Of the 20,000 people known to be sterilized in California under eugenic laws, only 831 were likely to be alive in 2016, and the average age of those survivors would have been 87.9 years at that time. ${ }^{19}$ There is little in the historical

\footnotetext{
${ }^{15}$ Mooten (2106) p 14.

16 Agostino, "Care."

${ }^{17}$ Following Doyle Srader's articulation of a performative or illocutionary listening which does work in the world in addition to the locutionary function of understanding, I use "listening toward" to signal the relational nature of this kind of listening.

${ }^{18}$ For more on the historicity of 'voice' see M. L. Crossley and N. Crossley, "'patient' Voices, Social Movements and the Habitus; How Psychiatric Survivors Speak Out," Social Science \& Medicine 52, no. 10 (2001): 1477-89. Perhaps the most well-cited piece on the problems of "giving voice" is Spivak's "Can the Subaltern Speak?" in Marxism and the Interpretation of Culture, edited by Cary Nelson and Lawrence Grossberg (Basingstoke: Macmillan Education, 1988), 271-313. For discussions of historical disclosure and large-scale accountability see: Matthew Colton, Maurice Vanstone, and Christine Walby, "Victimization, Care and Justice: Reflections on the Experiences of Victims/Survivors Involved in Large-scale Historical Investigations of Child Sexual Abuse in Residential Institutions," The British Journal of Social Work 32, no. 5 (August 2002): 541-51. 19 Alexandra Minna Stern, Nicole L. Novak, Natalie Lira, Kate O'Connor, Siobán Harlow, and Sharon Kardia, "California's Sterilization Survivors: An Estimate and Call for Redress," American Journal of Public Health 107, no. 1 (2017): 50-4.
} 
records that we have been able to locate that is written in the words of sterilization survivors. Given these two realities, listening to survivors on their own terms is becoming increasingly impossible. In the case of eugenic sterilization, we have a situation in which human mortality and legal protection of patient privacy are converging to produce a kind of historical amnesia. Fewer survivors can tell their own stories, and historians are limited in the kinds of storytelling we can engage in. As a consequence, we risk a future in which the general public of the United States and beyond is largely unaware of the individual and collective impacts of eugenic practices in the 20th century.

Accordingly, we found ourselves asking: How can we listen to such stories when the majority of our survivors have died, and we have little to nothing in their own words? This is a critical question in a situation such as eugenic sterilization in the United States, in which reproductive and disability rights have been violated in ways that also evidence racial bias. Failure both to recognize and redress such violations undermines accountability for past harms and ramifies through our current efforts to create more equitable futures.

Sonification is the translation of data - in this case data in .csv format - into sound, and it has been used to support learning for low-vision, blind, and neurodivergent individuals, a population that would have been targeted for eugenic sterilization. ${ }^{20}$ Sonification might render this history accessible to the very individuals targeted as "unfit" due to physical or cognitive disability. Additionally, the abstraction needed to sonify the collection enables us to address our collective goal to invert the power dynamics inscribed in the required anonymity of our records, where the state and medical establishment has largely been able to sequester this history behind the front of patient privacy. Sonification was one way to use the shield of patient protections to place a more intense spotlight on state and institutional actors who had violated individuals in such a profound and lasting way. Because we are unable to listen to survivors of eugenic sterilization, sonification would allow me to create the means to listen toward them in order to better understand past violations and to create new reparative possibilities.

While I was exploring sonification techniques, collaborators on the larger project uncovered data revealing that patients with Spanish or Hispanic surnames were three

\footnotetext{
${ }^{20}$ Michael Banf and Volker Blanz, "Sonification of Images for the Visually Impaired Using a Multi-Level Approach," $\mathrm{AH}$ '13: Proceedings of the 4th Augmented Human International Conference (March 2013): 162-9. Sonification has also been used by engineers exploring large datasets related to railways and cybersecurity because it can out-perform visual analysis. See: Tobias Hildebrandt, Thomas Hermann, and Stefanie Rinderle-Ma, "Continuous Sonification Enhances Adequacy of Interactions in Peripheral Process Monitoring," International Journal of Human-Computer Studies 95, issue C (November 2016): 54-65; and Mohamed Debashi and Paul Vickers, "Sonification of Network Traffic Flow for Monitoring and Situational Awareness," PLOS ONE 13, no. 4 (April 2018).
} 
times as likely to be sterilized as their non-Hispanic counterparts. ${ }^{21}$ The records also make clear that racist narratives about hyperfertility and fear of immigrants played a role in decisions about sterilization. As a proof of concept, I sonified selections of the data that highlight this tragic over-representation. In brief, this sonification process entails the following steps:

1. Select a subset of the larger dataset in order to work through the technical and historiographic processes,

2. Choose between two and four variables, such as gender, race, age at sterilization recommendation, consent, or nationality, and

3. Map the values into numerical space; because of how sound is produced by speakers, sonification requires the creation of a dataset whose limits are 1 and $-1$.

I did this work using two tools: an open-source tool developed at the University of Georgia known as Sonfication Sandbox, and GarageBand, a proprietary music-making tool that comes with Macintosh computers. I used Sonification Sandbox to create the score first and then turned to GarageBand because it has a greater range of instrumentation available. While large-scale sonification has been done by scholars and artists working in digital music and the sciences, the process for sonification is still rooted in particular project goals and, in this case, is relatively experimental and exploratory.

\section{LISTENING TO THE LISTENERS}

The larger Sterilization and Social Justice Lab project team develops and maintains relationships in a number of ways, including working with advocacy groups and communities in California. For me, the entry point into encounters with living communities was through my collaborator and critical data artist, Jessica Rajko, who theorizes and practices the kind of listening and reciprocity called for by care ethics. ${ }^{22}$ My training and background varies greatly from this process; to be honest, as a person trained to give papers and to receive and give critique, but not necessarily to be engaged in a reciprocal relationship, working directly with affected community groups was deeply unfamiliar and often uncomfortable for me. ${ }^{23}$ That discomfort, though, is necessary if we

\footnotetext{
${ }^{21}$ Nicole L. Novak et al., "Disproportionate Sterilization of Latinos."

${ }^{22}$ Jessica Rajko, "A Call to Action: Embodied Thinking and Human-Computer Interaction Design," in The Routledge Companion to Media Studies and Digital Humanities (New York: Routledge, 2018); and Jessica Rajko, Michael Krzyzaniak, Jacqueline Wernimont, Eileen Standley, and Stjepan Rajko, "Touching Data Through Personal Devices," MOCO '16: Proceedings of the 3rd International Symposium on Movement and Computing (July 2019): 1-8.

${ }^{23}$ I shared the sonifications at several events in 2016-2017 and published a brief on them in Sounding Out, https://soundstudiesblog.com/2016/07/18/hearing-eugenics/.I also hosted a set of conversations on eugenics and storytelling at Arizona State University.
} 
are to make good on feminist arguments that affect and relationships are essential in building knowledge.

The sonifications were used for both auditory and haptic presentation of the Spanish surname data. Haptic presentations are touch-based experiences that multiply the senses one can engage using the sonifications. In these demonstrations, the sonifications played through small vibrational devices called "woojers," which were used to transmit the sonification through tactile media like rubber, wire, and wood. Audience members were invited, but not required, to engage with the sound, the haptics, or both. During each presentation, the sonic and haptic elements were introduced and explained well in advance so that people in the audience had time to opt out by leaving the room or remaining seated before the playback began.
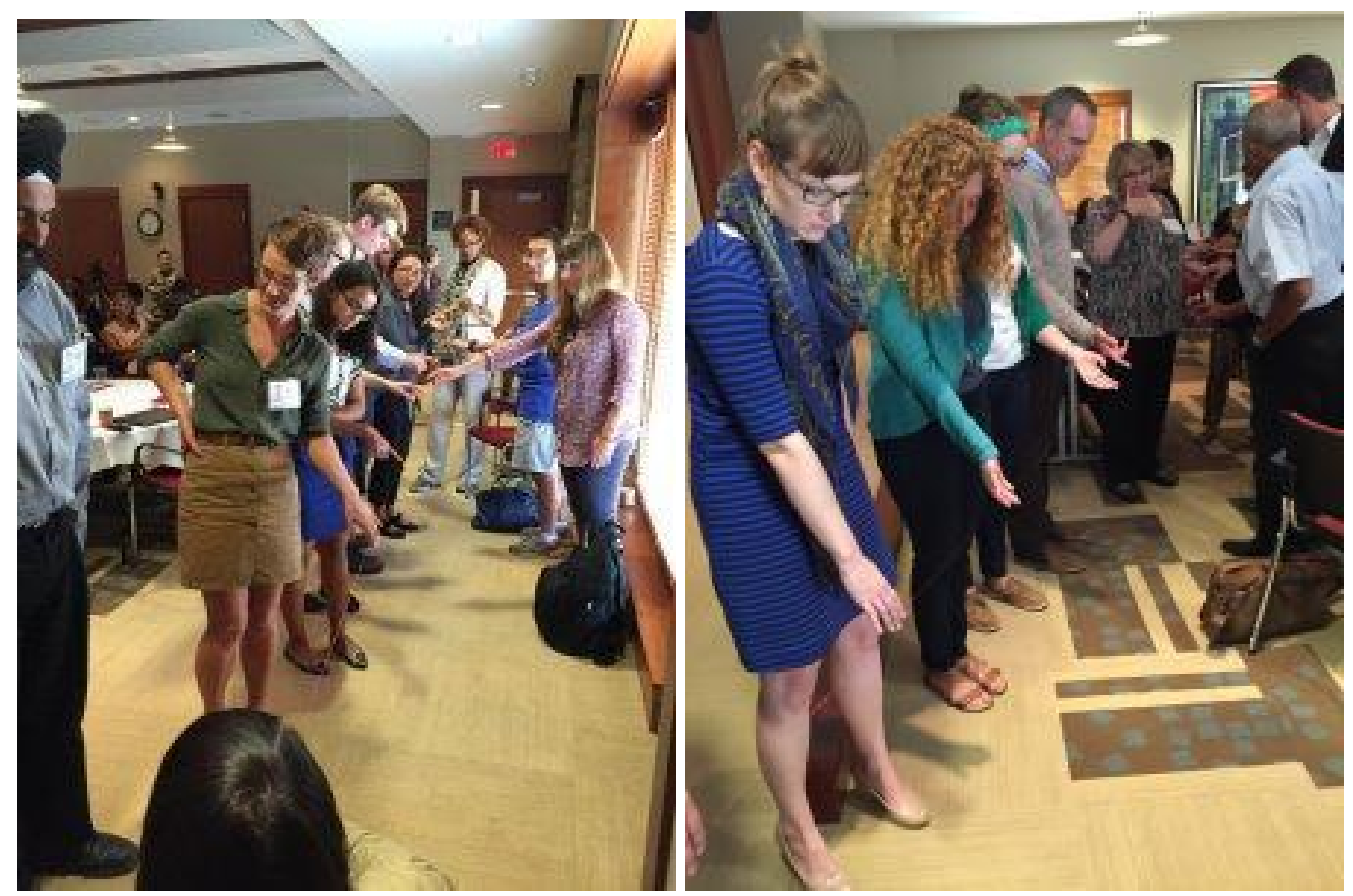

Image One and Image Two. Participants listening at a presentation at the University of Kansas. Photo by Elika Ortega. 


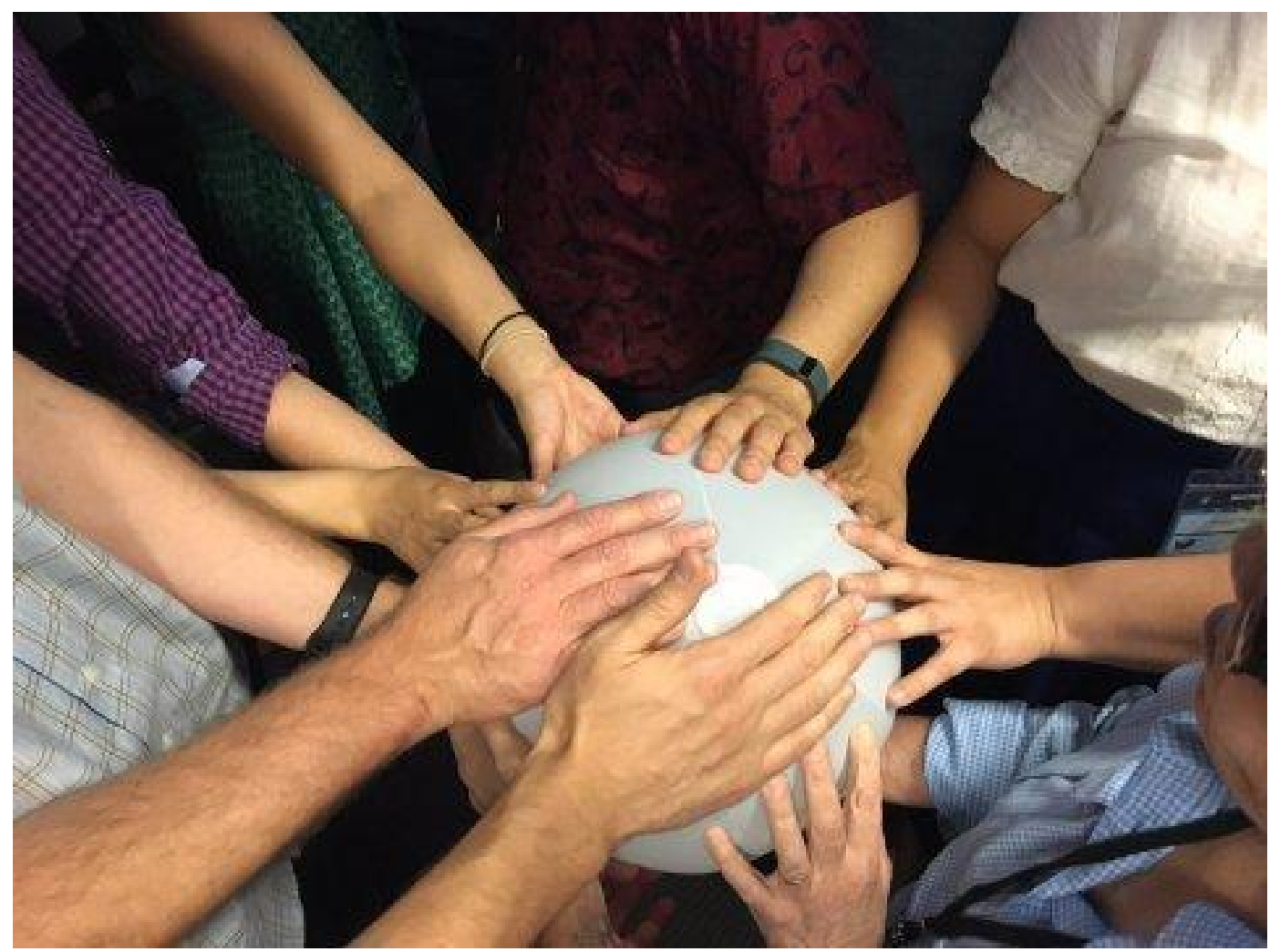

Image Three. Presentation of Latinx sonification at Arizona State University. Photo by Jasmine Rault.

In each of the foregoing images, the participants are engaged in a shared act of listening and feeling, developing a 'connected knowing' that depends on a social validation of truth and multiple situated knowledge producers. ${ }^{24}$ While one could certainly listen to the track while alone, and in fact readers of this piece might well do so, during these presentations I created spaces of collective experience wherein activation of the collection could be processed in community rather than isolation. ${ }^{25}$ Not only could the knowledge produced be connected and situated, these collective experiences could help ameliorate the risks of secondary trauma from engaging with records of violence against bodies, peoples, communities, and futures. ${ }^{26}$

\footnotetext{
${ }^{24}$ See, for example, Patricia Hill Collins' description of Black feminist epistemology in Black Feminist Thought.

${ }^{25}$ For a discussion of the activation of archives of human right abuses, see Michelle Caswell, "Defining Human Rights Archives: Introduction to the Special Double Issue on Archives and Human Rights," Archival Science 14 (2014): 207-13.

${ }^{26}$ For more on this phenomenon, see: Katie Sloan, Jennifer Vanderfluit, and Jennifer Douglas, "Not 'Just My Problem to Handle': Emerging Themes on Secondary Trauma and Archivists," Journal of Contemporary Archival Studies 6, no. 20 (2019); Kirsten Wright and Nicola Laurent,
} 
In Images One and Two, the sound is playing along a thin red wire that is sensitive to the dampening effects of others; in order for people to feel the data all the way down the line, the people closer to the woojer have to use a light touch. Similarly, on the ball in Image Three, if anyone were to hold too tightly or across too much space, the signal would be significantly dampened. Form and content are always intertwined, and one of my goals here was to create an experience where listening and feeling toward had to be enacted with care for the others in the room as well as those represented in the data. In caring enough for one another to allow the sounds and vibrations to move through the media, participants perform the very kind of attention to the needs of an other that is so clearly not present in the history of eugenic sterilization. While that responsiveness to an other in a room is not enough to manifest care ethics (it might just be public courtesy), it does begin to ground the presentation of the work in the kinds of formal and affective modes characteristic of its practice. There is also a physical expression of attention when people engage with the sonification and haptification; people lean in, some with eyes closed, others with a soft focus on a distant point, their heads lowered in a posture of intense focus ve. Sound and touch may well encode history differently than sight, and they certainly put us in a different physical relation to one another and the past.

Often, the presentations of the sonifications and the eugenics research were followed by extended dialogues in which I asked participants to share feedback and responses. While there were a variety of individual responses, several themes stood out. Many said they felt responsible to feel and hear each person and so stayed throughout the duration of the piece (just under two minutes) despite finding the material difficult. One participant indicated that she felt "more implicated," having engaged with an embodied experience than she would have if she had just been shown a visual such as a graph or chart. I hear in this particular observation that the process of bearing witness means that "we cannot say that we do not know." ${ }^{27}$ Not everyone found the transformation of data into sound and vibration compelling, however. Interestingly a single complaint surfaced across the first several presentations: that the data was imprecisely conveyed via sound and touch. Some people were frustrated that they could not see the entirety of the data at a glance and that information was not clearly labeled or defined when rendered as sound. In short, these participants preferred graphs and data tables.

I was well prepared to counter the complaints of empirically-minded audience members - I do not believe that we can accurately and objectively represent history in any context. I find the obfuscation of the sonification to be a useful formal expression of my commitment to listening toward rather than imagining that I can listen to the

\footnotetext{
"Safety, Collaboration, and Empowerment: Trauma-Informed Archival Practice," Archivaria 91 (2021): 38-73.

27 Mette Mortensen, “Connective Witnessing: Reconfiguring the Relationship between the Individual and the Collective," Information, Communication and Society 8, no. 11 (July 2015): 1398.
} 
survivors of eugenic sterilization. The other kind of objection that I received was not of the sort that one simply counters, not within an ethics of care framework. Two audience members present at the Latin American Studies Association (LASA) presentation voiced their discomfort with the sonification and haptification of the Spanish surname dataset. One shared that she was uncomfortable with the cultural position of the woojers, which were developed for video gaming. Her feelings were that using game technology, contextualized for her in terms of her own children's video game playing, was inappropriate for the communication of such sensitive data. Another colleague separately shared that she was uncomfortable with a white scholar, who enjoys significant privilege in the academy, making something akin to art out of the injustices wrought by white historical actors on Latinx bodies.

\section{STEPPING BACK AND IMPLICATIONS FOR COLLECTIONS AS DATA}

After LASA, I stopped working with the Spanish surname dataset, and I also stopped sonifying data from the project, although I continued to work with sonification in other projects. This was partly practical: I had a book manuscript to finish, and I would soon be taking a new job across the country. But it was also a conscious effort to step back and take time to process the range of feedback I had received on this particular sonification work. I wanted to take seriously what colleagues and community members in a variety of settings had offered me. I wanted to understand where the remediation or translation of the collection as data might cause harm and where it might open up opportunities. I needed to integrate what I had learned in order to potentially continue or move in alternative directions.

In the intervening four years, care ethics has been popular within certain digital humanities and archival studies conversations. ${ }^{28}$ Collections as data is also an idea and a practice that has rapidly taken hold with major research initiatives, training sessions at digital humanities and library conferences, and convenings, including the one that precipitated this special issue. ${ }^{29}$ While collections as data is not a domain in which I am

\footnotetext{
${ }^{28}$ For example: Daniela Agostinho, "Archival encounters: Rethinking access and care in digital colonial archives," Archival Science 19 (2019): 141-165; Stacie Williams, "All Labor is Local," presented at the 2016 Digital Library Federation Forum, published on Medium, Nov. 12, 2016, https://medium.com/@Wribrarian/all-labor-is-local-344963e33051; and Chelcie Juliet Rowell and Taryn Cooksey, "The Archive of Hate: Ethics of Care in the Preservation of Ugly Histories," Lady Science, January 9, 2019, https://www.ladyscience.com/essays/archive-of-hate-ethics-of-care-in-the-preservation-of-ugly-h istories. In Digital Humanities, see for example: Todd Suomela, Florence Chee, Bettina Berendt, and Geoffrey Rockwell, "Applying an Ethics of Care to Internet Research: Gamergate and Digital Humanities," Digital Studies/Le Champ Numérique 9, no. 1 (2019); Shawna Ross, "Toward a feminist modernist digital humanities," Feminist Modernist Studies 1, no. 3, (2018): 211-29; and Jacqueline Wernimont, "Knowing Why Revolution Must Come: Digital Humanities as Poetry and Prayer," American Quarterly 70, no. 3 (Sept. 2018): 671-675.

${ }^{29}$ See also: Thomas Padilla, "On a Collections as Data Imperative," (2017); and Rachel Wittmann, Anna Neatrour, Rebekah Cummings, and Jeremy Myntti, "From Digital Library to Open Datasets:
} 
an expert, the use of archival records and materials in Eugenic Rubicon has given me an opportunity to think through how sensitive datasets and records of human rights abuses warrant a different kind of attention in the collections-as-data conversation. We are, I hope, well beyond the notion that what we do with and through collections is 'give voice': voice is not something to be given. People already have a voice even if they have been structurally marginalized and disenfranchised. ${ }^{30}$ Similarly, primary documents have usefully been troubled as a way to 'see' or 'read' the past given our longstanding recognitions of the way that power mediates who gets to write, what they get to write, how collections are formed and maintained, and even our reading practices as historians. The documentary record is a mediated record, one that offers partial views from particular places. An ethical approach entails knowing the context of a document's creation and circulation, as well as attending to the ways their forms shape their meanings.

An ethics of care insists that we deepen our practices of listening. How do we understand this mandate when we have a bureaucratic textual record and not much else, as in the case of eugenic sterilization records? Sonification may well be an avenue for 21st-century audiences to use a wide array of modalities for engaging with the past. Sonification and haptics created from data about cultural heritage collections may also offer us a way to create new paths of accessibility to largely textual and visual materials. The methods and tools of sonification and haptics carry their own historical situatedness, however, and they may also have associative and material connections that trouble their easy use. It additionally matters who is doing this work and how they are situated relative to the histories being told. Part of what my experience with Eugenic Rubicon has taught me is that we cannot assume that the existence of records of human rights violations justifies telling the story without regard to community harm. Understanding relationality as a way of responsibly engaging requires us to recognize that we are responsible to a multitude of others. We become answerable to feelings that we may not or cannot share, and which are structured within asymmetries of power. Disregarding this threatens to elongate the havoc wreaked through imperial modes of being and knowing. Feminist care ethics demand that we acknowledge our own situatedness as scholars and admit the possibility that some stories are not ours to tell. When and if we are able to responsibly bring such stories to light with communities, we also have to be ready to deal with the trauma these histories may reactivate. This is not work to be taken lightly.

A scholar can inadvertently reactivate trauma even when one is not making more abstracted and artistic interventions. On example is the following story from when

Embracing a 'Collections as Data' Framework," Information Technology and Libraries 38, no. 4 (2019): 49-61. Grants include "Using Newspapers as Data for Collaborative Pedagogy: A Multidisciplinary Interrogation of the Borderlands in Undergraduate Classrooms," University of Arizona and "Collections As Data: Always Already Computational," which is part of the IMLS new funding program on the topic.

${ }^{30}$ See note 9 above. 
we worked with a group of educators during a Facing History | Facing Ourselves (FHFO) summer training in California. This was a part of our effort to engage disability and reproductive rights communities in California to test our prototype website for Eugenic Rubicon. We had planned to join one day of the extended FHFO training in order to share our research and to understand how the website and other tools might best serve teachers in the primary school systems in California. In addition to a presentation and discussion, we introduced teachers to the resources on the site and conducted usability testing with that group. (We followed much the same process with disability rights groups and reproductive justice advocates during that same trip).

I sat alongside a participant as they began navigating the prototype site. As they moved through the materials, I could feel something change-their body became a bit more rigid, their jaw a little more set, their time on pages longer and quieter. I asked how things were going and if there was anything I could do to help. Their response: "I think I need a minute." We both paused and then this participant said, "I think a family member is a part of this story." My role suddenly changed. Instead of a demonstration leader I was a person who cared about another person processing potentially traumatic new knowledge. I was there to bear witness and be with, not to offer technical support and certainly not to get feedback on design and usability. This participant had not come into the workshop knowing that eugenic sterilization was a part of their family's history. Prior to using our digital publication, they had only fragments of stories about a particular relative in a particular hospital during a particular time. As they began to work with the site, pieces that had been disjointed began to fit together, snapping together suddenly in a high school room surrounded by strangers that day.

I share this story as a way of building on some of the insights gained when presenting the sonifications and as a way of expanding out into less "experimental" modes of engaging collections as data. This particular experience offers a view on the ways that the histories represented in our collections are a part of the histories that we occupy today. We have to grapple not only with how different modalities and tools might be understood vis-a-vis the story being told and the people telling the story, but also with the reality that trauma has a long half-life, and it is not possible to know when or where the boundaries between private family histories and public reckonings will blur or dissolve entirely. This is one of the insights of feminist care ethics: that the modalities and insights of the private sphere can and should structure the public sphere.

This can be a difficult point to make with people who are accustomed to using anything present in the archive, who are trained in the idea of objective analysis of historical materials. Nor is it easy to maintain the standards we use in intimate relationships when someone is convinced that justice demands we highlight human rights abuses. Within ethics and philosophy there is an ongoing discussion of whether ethics of care and justice are compatible.

Often I encounter historians, library and archives professionals, or information professionals who argue that justice demands that all of the history of eugenic sterilization be brought into the light with as much transparency and immediacy as 
possible. This argument is mirrored in contemporary discussions about collecting and archiving social media. For example, at the University of Michigan Web Archives 2015 conference, keynote speaker Jefferson Bailey (Director of Web Archiving and Data Services at Internet Archive) replied to the suggestion that minoritized people may not want their social media posts archived for fear of state action with a curt suggestion that "they don't know what's good for them." 31 The "information wants to be free" Silicon-Valley ethos often finds its mirror in academic and archival adherence to the idea that historical transparency is an unalloyed good. As Thomas Padilla has noted, there are fundamental tensions between calls for ethical use of collections and "the right to mine" discourses that see cultural heritage data as yet another site of data optimization and opportunity. ${ }^{32}$

Feminist care informs approaches to archives that repudiate an extractive approach to cultural heritage and draw our attention to the affective and relational nature of our work. In situations such as the one described in this case study, our approach should be one of dialogue and learning, a slow process grounded in understanding the power dynamics in all of our relationships, even those relationships that we might deprioritize as merely professional. Bethany Nowviskie has termed a sort of professional entanglement as "engrossment" and calls us to work as deeply, as carefully, and with as much commitment as we do in our intimate spaces. ${ }^{33}$ We have to do the tender work of addressing and redressing the inequities in our current social structures, which live on in our archives and cultural heritage institutions. This is not work for the impatient, but I think it is some of the most important work we can do.

\footnotetext{
${ }^{31}$ Bailey keynoted the Web Archiving Conference at University of Michigan, November 12-13, 2015.

32 Thomas Padilla, "Collections as Data: Implications for Enclosure," College \& Research Libraries News 79, no. 6 (2018): 296.

${ }^{33}$ Bethany Nowviskie, "Capacity Through Care," in Debates in the Digital Humanities 2019, edited by Matthew K. Gold and Lauren F. Klein (Minneapolis: U of Minnesota P, 2019), 424-26.
} 


\section{ACKNOWLEDGEMENTS}

I am grateful for the extensive comments on various drafts of this article from Carolyn Dever, Nikki Stevens, Leah PoweLl, and Sophia Zeigler. It is better for their engagement and all failings remain my own. 


\section{BIBLIOGRAPHY}

Agostinho, Daniela. "Archival Encounters: Rethinking Access and Care in Digital Colonial Archives." Archival Science 19 (2019): 141-165. https://doi.org/10.1007/s10502-019-09312-0.

Agostino, Daniela. "Care." In Uncertain Archives: Critical Keywords for Big Data, edited by Nanna Bonde Thylstrup et al, 75-86. Cambridge: MIT, 2021. https://www.academia.edu/45184300/Care.

Bailey, Moya. "\#transform(Ing) DH Writing and Research: An Autoethnography of Digital Humanities and Feminist Ethics." Digital Humanities Quarterly 9, no. 2 (2015). http://www.digitalhumanities.org/dhq/vol/9/2/000209/000209.html.

Banf, Michael, and Volker Blanz. "Sonification of Images for the Visually Impaired Using a Multi-Level Approach." AH '13: Proceedings of the 4th Augmented Human International Conference (March 2013): 162-9. https://doi.org/10.1145/2459236.2459264.

Butler, Fred O. "Report to Department of Institutions." California State Printing Office, 1926.

Caswell, Michelle, and Marika Cifor. "From Human Rights to Feminist Ethics: Radical Empathy in the Archives." Archivaria 81 (Spring 2016): 23-43. https://escholarship.org/uc/item/0mb9568h.

Caswell, Michelle. "Defining Human Rights Archives: Introduction to the Special Double Issue on Archives and Human Rights." Archival Science 14 (2014): 207-13. https://doi.org/10.1007/s10502-014-9226-0.

Collins, Patricia Hill. Black Feminist Thought. New York: Routledge, 1990.

Colton, Matthew, Maurice Vanstone, and Christine Walby. "Victimization, Care and Justice: Reflections on the Experiences of Victims/Survivors Involved in Large-scale Historical Investigations of Child Sexual Abuse in Residential Institutions." The British Journal of Social Work 32, no. 5 (August 2002): 541-51. https://doi.org/10.1093/bjsw/32.5.541.

Crossley, M. L. and N. Crossley. "'Patient' Voices, Social Movements and the Habitus; How Psychiatric Survivors 'Speak Out.'" Social Science \& Medicine 52, no. 10 (May 2001): 1477-89. https://doi.org/10.1016/S0277-9536(00)00257-4.

Debashi, Mohamed, and Paul Vickers. "Sonification of Network Traffic Flow for Monitoring and Situational Awareness." PLOS ONE 13, no. 4 (April 2018). https://doi.org/10.1371/journal.pone.0195948. 
Estrella, Amarilys, and Meryleen Mena. “Guest Post: Black Latinx Encuentros: Embodied Knowledge and Reciprocal Forms of Knowledge Sharing [Embodying Reciprocity Series]." Footnotes, July 1, 2020.

https://footnotesblog.com/2020/07/01/guest-post-black-latinx-encuentros-emb odied-knowledge-and-reciprocal-forms-of-knowledge-sharing/.

Graham, Mary. "Aboriginal Notions of Relationality and Positionalism: A Reply to Weber." Global Discourse 4, no. 1 (Jan. 2014): 17-22.

https://doi.org/10.1080/23269995.2014.895931.

Hartman, Saidiya. Scenes of Subjection:Terror, Slavery, and Self-Making in Nineteenth-Century America. Oxford: Oxford UP, 1997.

Hildebrandt, Tobias, Thomas Hermann, and Stefanie Rinderle-Ma. "Continuous Sonification Enhances Adequacy of Interactions in Peripheral Process Monitoring." International Journal of Human-Computer Studies 95, issue C (November 2016): 54-65. https://doi.org/10.1016/j.ijhcs.2016.06.002.

LaPensée, Elizabeth. "Relationality in Indigenous Food and Medicine Games." Resilience: A Journal of Environmental Humanities 4, no. 2 (2017): 191-200. https://doi.org/10.5250/resilience.4.2-3.0191.

Lawrence, Susan C. Privacy and the Past: Research, Law, Archives, Ethics. New Jersey: Routledge, 2016.

Mooten, Nalini. "Toward a Postcolonial Ethics of Care." Dec. 18, 2016. https://ethicsofcare.org/wp-content/uploads/2016/12/Toward a Postcolonial Ethics of Care.pdf.

Mortensen, Mette. "Connective Witnessing: Reconfiguring the Relationship between the Individual and the Collective." Information, Communication and Society 8, no. 11 (July 2015): 1398-1406. https://doi.org/10.1080/1369118X.2015.1061574.

Narayan, Uma. "Colonialism and Its Others: Considerations On Rights and Care Discourses." Hypatia 10, no. 2 (Spring 1995): 133-40. https://doi.org/10.1111/i.1527-2001.1995.tb01375.x.

Novak, Nicole L., Natalie Lira, Kate E. O’Connor, Siobán D. Harlow, Sharon L. R. Kardia, and Alexandra Minna Stern. "Disproportionate Sterilization of Latinos Under California's Eugenic Sterilization Program, 1920-1945." American Journal of Public Health 108, no. 5 (2018): 611-13. https://doi.org/10.2105/AJPH.2018.304369. 
Nowviskie, Bethany. “Capacity Through Care." In Debates in the Digital Humanities 2019, edited by Matthew K. Gold and Lauren F. Klein, 424-26. Minneapolis: U of Minnesota P, 2019.

Padilla, Thomas. "Collections as Data: Implications for Enclosure." College \& Research Libraries News 79, no. 6 (2018): 296. https://doi.org/10.5860/crln.79.6.296.

Padilla, Thomas. "On a Collections as Data Imperative." (2017). https://labs.loc.gov/static/labs/work/reports/tpadilla OnaCollectionsasDatalmp erative final.pdf.

Rajko, Jessica. "A Call to Action: Embodied Thinking and Human-Computer Interaction Design." In The Routledge Companion to Media Studies and Digital Humanities, edited by Jentery Sayers, 195-203. New York: Routledge, 2018.

Rajko, Jessica, Michael Krzyzaniak, Jacqueline Wernimont, Eileen Standley, and Stjepan Rajko. "Touching Data Through Personal Devices." MOCO '16: Proceedings of the 3rd International Symposium on Movement and Computing (July 2019): 1-8. https://doi.org/10.1145/2948910.2948937.

Ross, Shawna. "Toward a Feminist Modernist Digital Humanities." Feminist Modernist Studies 1, no. 3 (2018): 211-29. https://doi.org/10.1080/24692921.2018.1505821.

Rowell, Chelcie Juliet, and Taryn Cooksey. "The Archive of Hate: Ethics of Care in the Preservation of Ugly Histories." Lady Science. January 9, 2019.

https://www.ladyscience.com/essays/archive-of-hate-ethics-of-care-in-the-prese rvation-of-ugly-histories.

Schaffer, Kay and Sidonie Smith. Human Rights and Narrated Lives: The Ethics of Recognition. New York: Palgrave Mcmillian, 2004.

Sloan, Katie, Jennifer Vanderfluit, and Jennifer Douglas. "Not 'Just My Problem to Handle': Emerging Themes on Secondary Trauma and Archivists." Journal of Contemporary Archival Studies 6, no. 20 (2019). https://elischolar.library.yale.edu/icas/vol6/iss1/20.

Smith, Barbara. "Toward a Black Feminist Criticism." The Radical Teacher 7 (March 1978): 20-27. http://www.jstor.org/stable/20709102.

Sontag, Susan. Regarding the Pain of Others. New York: Picador, 2003.

Spivak, Gayatri Chakravorty. "Can the Subaltern Speak?" In Marxism and the Interpretation of Culture, edited by Cary Nelson and Lawrence Grossberg, 271-313. Basingstoke: Macmillan Education, 1988. 
Stern, Alexandra Minna, Nicole L. Novak, Natalie Lira, Kate O'Connor, Siobán Harlow, and Sharon Kardia. "California's Sterilization Survivors: An Estimate and Call for Redress." American Journal of Public Health 107, no. 1 (January 2017): 50-54. https://doi.org/10.2105/AJPH.2016.303489.

Stern, Alexandra Minna. "Remembering Sara Rosas Garcia." Process: A Blog for American History. February 7, 2017. http://www.processhistory.org/sara-rosas-garcia/.

Suomela, Todd, Florence Chee, Bettina Berendt, and Geoffrey Rockwell. "Applying an Ethics of Care to Internet Research: Gamergate and Digital Humanities." Digital Studies/Le Champ Numérique 9, no. 1 (2019). http://doi.org/10.16995/dscn.302.

Sutherland, Tonia. "'Making A Killing': On Race, Ritual, and (Re)Membering in Digital Culture." Preservation, Digital Technology and Culture 46, no. 1 (2017): 32-40. https://doi.org/10.1515/pdtc-2017-0025.

Sutherland, Tonia. "Remains." In Uncertain Archives: Critical Keywords for Big Data, edited by Nanna Bonde Thylstrup et al., 433-42. Cambridge: MIT, 2021.

Tronto, Joan. Caring Democracy: Markets, Equality and Justice. New York: NYU Press, 2013.

Wernimont, Jacqueline. "Knowing Why Revolution Must Come: Digital Humanities as Poetry and Prayer." American Quarterly 70, no. 3 (September 2018): 671-75. https://doi.org/10.1353/aq.2018.0051.

Williams, Stacie. "All Labor is Local." Presented at the 2016 Digital Library Federation Forum. Published on Medium, Nov. 12, 2016, https://medium.com/@Wribrarian/all-labor-is-local-344963e33051.

Wilson, Shawn. Research Is Ceremony: Indigenous Research Methods. Halifax: Fernwood Publishing, 2008.

Wittmann, Rachel, Anna Neatrour, Rebekah Cummings, and Jeremy Myntti. "From Digital Library to Open Datasets: Embracing a 'Collections as Data' Framework." Information Technology and Libraries 38, no. 4 (2019): 49-61. https://doi.org/10.6017/ital.v38i4.11101.

Wright, Kirsten, and Nicola Laurent. "Safety, Collaboration, and Empowerment: Trauma-Informed Archival Practice." Archivaria 91 (June 2021): 38-73. https://archivaria.ca/index.php/archivaria/article/view/13787. 